\title{
Model Mesin Stirling 3D Printing Sebagai Media Belajar Fisika Materi Termodinamika
}

\author{
Ida Kristiani ${ }^{1}$, Wahyu H. Kristiyanto ${ }^{1,2}$, Ferdy S. Rondonuwu ${ }^{1,2, *}$ \\ ${ }^{1} J u r u s a n$ Pendidikan Fisika, Fakultas Sains dan Matematika, UKSW \\ ${ }^{2}$ Pusat Studi Sains, Teknologi, dan Matematika, Fakultas Sains dan Matematika, UKSW \\ Jalan Diponegoro 52 - 60, Salatiga, Jawa Tengah 50711 \\ *email korespondensi: ferdy.rondonuwu@uksw.edu
}

Received : 2 Januari 2020; Revised : 24 Januari 2020; Accepted : 21 Mei 2020; Published : 30 Mei 2020

\begin{abstract}
ABSTRAK
Mesin Stirling merupakan teknologi yang memanfaatkan perbedaan suhu sebagai pendorong gerak berkelanjutan. Karena itu dari sudut pandang pembelajaran, konsep dasar dan prinsip kerja mesin ini sangat berguna untuk mendemonstrasikan aplikasi termodinamika dalam teknologi. Mesin Stirling sering diaplikasikan pada beberapa alat yang digunakan dalam kehidupan seperti mesin pembangkit listrik dan mesin motor. Mesin Stirling juga dapat dijadikan sebagai media belajar untuk mempermudah siswa dalam memahami materi termodinamika terkhusus hubungan Tekanan dan Volume $(p-V)$. Penelitian pengembangan ini bertujuan untuk menghasilkan model mesin Stirling dengan memanfaatkan teknologi 3D printing. Komponen-komponen mesin dirancang dengan perangkat lunak Autodesk Fusion 360 secara detail dan sesuai fungsinya. Keunggulan rancangan dengan memanfaatkan 3D Printing yaitu alat dapat bertahan lebih lama dan lebih ringan. Komponen ruang udara (chamber) memanfaatkan semprotan kaca (syringe) bervolume $10 \mathrm{~mL}$ sebanyak 2 buah. Sumber energi penggerak adalah nyala api dari pembakar spiritus. Hasil penelitian menunjukkan bahwa rancangan mesin Stirling 3D dapat beroperasi sesuai fungsinya dengan pemanasan dari pembakar spiritus pada salah satu silinder dipanaskan untuk mengubah tekanan dan suhunya. Keterbatasan rancangan mesin ini hanya dapat beroperasi kurang lebih selama 6 menit secara terus-menerus tanpa pendingin tambahan. Namun sebagai media pembelajaran yang dapat digunakan pada bagian proses pembalajaran, fungsi kerja 6 menit sudah baik sesuai proporsi alokasi waktu dalam kegiatan pembelajaran. Melalui mesin ini memungkinkan siswa untuk melakukan eksplorasi berbagai parameter yang menentukan kecepatan, lama operasi, dan kekuatan putar (torka) sehingga dapat menjadi media belajar yang interaktif. Simpulan penelitian ini adalah model mesin Stirling 3D Printing dapat digunakan sebagai media belajar Fisika materi Termodinamika.
\end{abstract}

Kata-kata kunci: fisika; media belajar; mesin Stirling; termodinamika; 3D printing.

\section{PENDAHULUAN}

Pembelajaran fisika seringkali disertai dengan eksperimen yang memerlukan sarana diantaranya laboratorium dan alat peraga (Helinda, 2016). Penggunaan alat peraga sangat penting sebagai sumber belajar untuk memperoleh informasi dan merangsang proses berpikir (kritis) peserta didik sehingga mendorong kreativitas dan membantu dalam pemecahan masalah (Saputro et al, 2019). Tidak semua alat tersedia dalam kegiatan eksperimen sehingga seringkali guru perlu mengembangkan media pembelajaran sesuai dengan konsep yang akan disampaikan. Alat-alat dalam kehidupan sehari-hari menggunakan prinsip kerja mesin Stirling diterapkan pada pompa air, mesin pembangkit listrik, dan mesin motor (Singh \& Kumar, 2018). Model mesin Stirling membantu mempelajari aplikasi dari panas atau energi dalam sistem melalui visualisasi sehingga menjadi media yang cocok dalam memahami materi termodinamika (Halliday et al, 2010). Mesin Stirling adalah mesin pembakaran eksternal yang menggunakan udara atau gas sebagai fluida kerjanya dengan prinsip regenerative siklus tertutup. Mesin ini masing-masing menjaga perbedaan suhu untuk dapat beroperasi (Romanelli, 2017; Walker, 1985; Yuliyani \& Irwan, 2013).

Perkembangan teknologi digital diera Industri 4.0 saat ini telah membawa perubahan dan mempengaruhi berbagai aspek kehidupan manusia. Salah satu yang memanfaatkan aspek tersebut adalah bidang pendidikan (Putrawangsa \& Hasanah, 2018). Perkembangan teknologi yang semakin pesat menuntut dunia pendidikan untuk meningkatkan mutunya, khususnya dalam pembelajaran. Mesin 3D 
printing merupakan salah satu teknologi yang sangat membantu dalam mewujudkan berbagai desain dan gagasan media pemebelajaran. Mesin 3D printing mencetak objek 3 dimensi dari model digital (Setyo \& Financia, 2018) di mana hasil cetakannya cukup awet dan tidak mudah rusak serta ringan.

Helinda (2016) dan Religia (2017) melakukan penelitian dengan mengembangkan mesin Stirling sederhana sebagai media belajar. Penggunaan media tersebut dapat meningkatkan hasil belajar dan memberikan ketertarikan pada siswa dalam belajar termodinamika. Peneliti merangkai mesin dengan menggunakan barang bekas seperti kaleng. Persoalan yang muncul dari penggunaan barang bekas sebagai bahan pembuatan mesin Stirling adalah kurang presisi, mudah lepas rangkaiannya, dan tidak mudah pengoperasiannya sehingga tidak praktis dan sulit digunakan dalam kelas (Helinda, 2016; Religia, 2017). Untuk itulah diperlukan model mesin Stirling yang dapat membantu mempermudah pembelajaran materi termodinamika, dengan bahan dan konstruksi yang lebih awet dan kuat. Tujuan penelitian ini adalah menghasilkan media yang bisa digunakan untuk membantu pembelajaran secara terus-menerus pada materi Termodinamika dengan teknologi digital 3D printing.

\section{METODE PENELITIAN}

\section{Prosedur Rancangan Dan Percetakan}

Terdapat 5 tahap yang dilakukan dalam merealisasikan mesin Stirling yaitu pembuatan gambar dan ukuran mesin, pemilihan bahan, pencetakan desain, perakitan, dan pengujian.

Tahap pembuatan gambar menggunakan software Autodesk Fusion 360 dilakukan untuk memudahkan pada tahap merancang mesin. Setelah selesai dirancang file nantinya kemudian diubah menjadi file dengan format '.STL' dengan aplikasi Meshmixer agar desain file dapat dibaca oleh mesin pencetak 3D.

Bahan yang dipakai untuk mencetak rancangan adalah PLA dalam bentuk filamen (lihat Gambar 1a) dan hasil cetakan ditunjukkan Gambar $\mathbf{1 b}$.

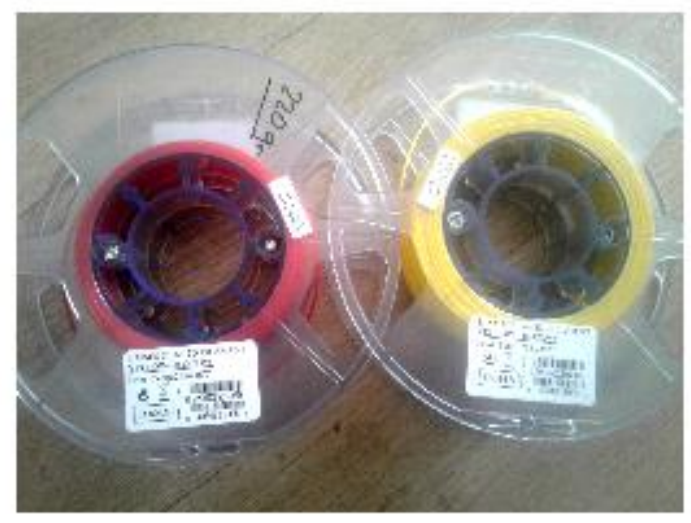

(a)

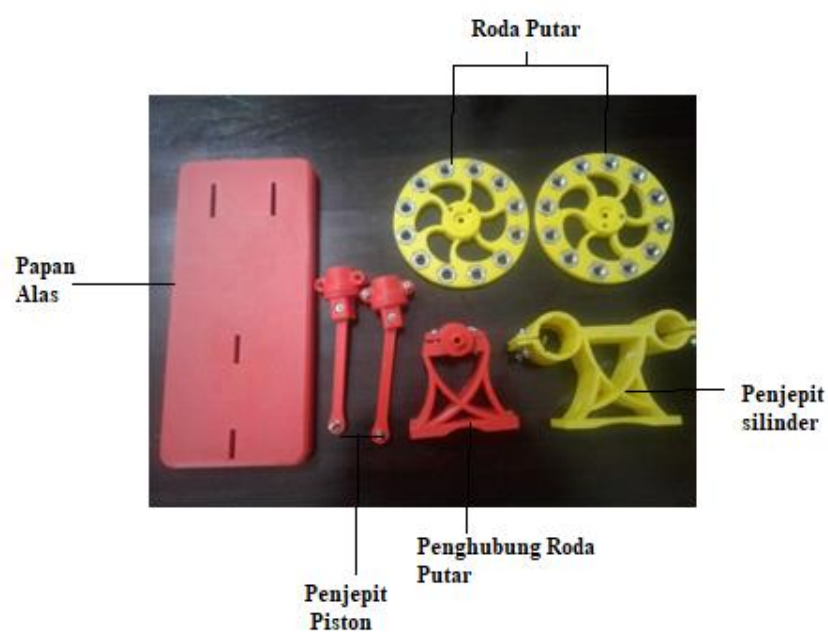

(b)

Gambar 1. (a) Filamen PLA sebagai bahan dasar pencetakan 3D dan (b) bagian-bagian mesin Stirling.

Bagian-bagian mesin Stirling terdiri dari papan alas yang berfungsi sebagai tempat memasang penjepit silinder dan penghubung roda putar. Roda berfungsi sebagai penggerak awal mesin. Penjepit piston berfungsi untuk tempat pendorong silinder kaca. Penjepit silinder terdiri dari dua lubang, berfungsi sebagai penyangga silinder kaca, dan penghubung roda putar berfungsi untuk menempelkan roda dengan penjepit piston. Bahan-bahan yang digunakan dalam perakitan adalah 2 buah silinder kaca dengan volume $10 \mathrm{~mL}$, selang tahan panas berbahan teflon, mur M14, mur, baut, dan spiritus. 


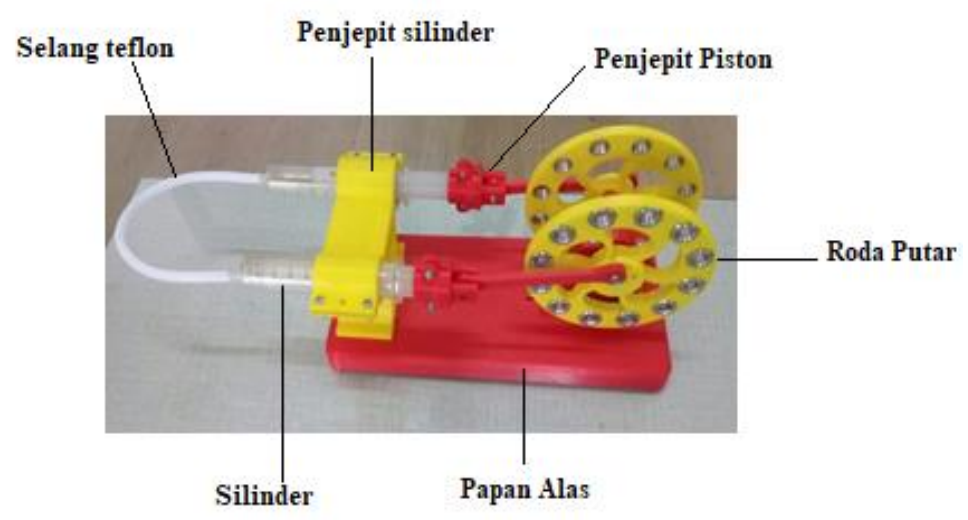

Gambar 2. Prototipe mesin Stirling.

Gambar 2 menunjukkan prototype mesin Stirling, di mana dua roda dipasang pada penghubung roda putar yang sudah menempel pada papan alas. Kemudian penjepit piston yang telah dipasang dengan pendorong silinder kaca dihubungkan pada roda. Penjepit silinder dipasang pada papan alas dan memasang silinder kaca pada lubang penjepit, di mana salah satu penjepit yang diameter lubang lebih besar diberi kayu sebagai isolator. Selanjutnya memasang selang teflon sebagai penghubung udara pada silinder suhu rendah dan silinder suhu tinggi.

Mesin Stirling yang dirancang adalah tipe Alfa, memiliki ukuran panjang $22 \mathrm{~cm}$; lebar $10 \mathrm{~cm}$; tinggi 9 $\mathrm{cm}$; diameter penjepit silinder suhu tinggi $2,5 \mathrm{~cm}$; diameter penjepit silinder suhu rendah $2 \mathrm{~cm}$; dan diameter roda $10 \mathrm{~cm}$. Roda dibuat lebih berat dengan menempelkan mur M14 sejumlah 12 buah pada setiap roda untuk menaikkan inersia dari roda supaya gerakan putarnya tidak mudah berhenti dan dengan memperbesar inersia akan membantu stabilitas dari gerakan bolak balik mesin. Penjepit silinder suhu tinggi didesain berdiameter lebih besar daripada penjepit silinder suhu rendah. Hal ini berfungsi untuk menambahkan bahan berupa kayu sebagai isolator pada mesin agar panas tidak cepat merambat dari silinder kaca ke penjepit silindernya. Kedua piston diolesi dengan brasso yang berfungsi untuk menghilangkan serpihan kaca dan memperhalus permukaan piston.

Gambar 3 menunjukkan uji coba untuk mengetahui kinerja dari mesin Stirling. Pengujian mesin menggunakan sumber panas yang diletakkan pada salah satu silinder.

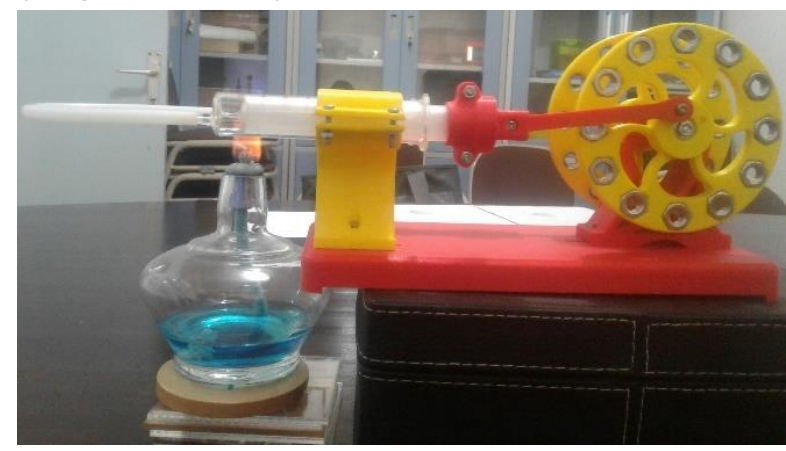

Gambar 3. Susunan percobaan mesin Stirling.

\section{HASIL DAN DISKUSI}

Hasil penelitian ini terdiri dari hasil kajian kebutuhan, hasil perancangan, dan hasil uji coba model mesin Stirling 3D. Hasil kajian kebutuhan didapatkan bahwa pada materi Fisika Termodinamika belum terdapat media pembelajaran mesin Stirling di laboratorium. Media pembelajaran mesin Stirling masih dalam bentuk gambar dan animasi simulasi komputer. Keterbatasan ini dikarenakan sulitnya membuat mesin ini yang dapat berfungsi baik dengan biaya yang cukup murah. Hasil kajian kebutuhan untuk menunjang ini ditemukan beberapa potensi untuk membuat mesin ini meskipun dalam bentuk prototype. Ketersediaan mesin printer 3D di laboratorium yang dimiliki Fakultas Sains dan Matematika Universitas 
Kristen Satya Wacana dapat memproduksi prototype 3D dengan ukuran dan bentuk sesuai rancangan serta tingkat presisi yang tinggi.

Hasil perancangan model mesin Stirling 3D ditunjukkan pada Gambar 1 dan 2. Hasil perancangan ini sesuai dengan hasil kajian kebutuhan yang telah dilakukan. Sesuai dengan prediksi di awal bahwa model mesin Stirling 3D dapat diwujudkan dalam bentuk prototype dengan bentuk, ukuran, dan presisi yang sangat baik. Prototype ini memiliki keterbatasan pada piston yang dapat memberikan kompresi yang baik melalui pemanasan masih sulit dibuat dengan bahan yang tersedia meskipun dengan menggunakan printer 3D. Keterbatasan ini menyebabkan pada bagian piston pengompres dipasang dengan menggunakan piston komersial yang tesedia di pasaran yang terbuat dari kaca.

Piston pengompres terdiri dari dua silinder yaitu silinder pertama untuk suhu tinggi dan silinder kedua untuk suhu rendah. Kedua silinder terhubung dengan selang teflon yang berfungsi sebagai pertukaran udara. Dua piston berada pada silinder terpisah tetapi dihubungkan ke poros yang sama, namun pergerakan dari kedua piston ini saling berlawanan arah. Saat poros berputar piston bergerak dengan fase konstan. Dua silinder diisi dengan massa udara tetap, yang didaur ulang dari silinder suhu tinggi ke silinder suhu rendah.

Hasil uji coba menunjukkan bahwa mesin Stirling tidak bekerja sesuai rancangan karena sumber panas yang digunakan adalah lilin. Sumber panas dari lilin belum mampu memanaskan silinder untuk menggerakkan mesin tersebut karena suhu yang dihasilkan dari nyala lilin kurang tinggi. Maka dilakukan perbaikan dan mengganti sumber panas dengan spiritus. Hasil pengujian membuktikan bahwa spiritus mampu menggerakkan mesin tersebut karena suhu dari spiritus lebih tinggi daripada lilin dibuktikan dari warna api yang berwarna biru (Gambar 3). Maka sumber panas inilah yang digunakan untuk menggerakkan piston dari silinder suhu tinggi ke silinder suhu rendah.

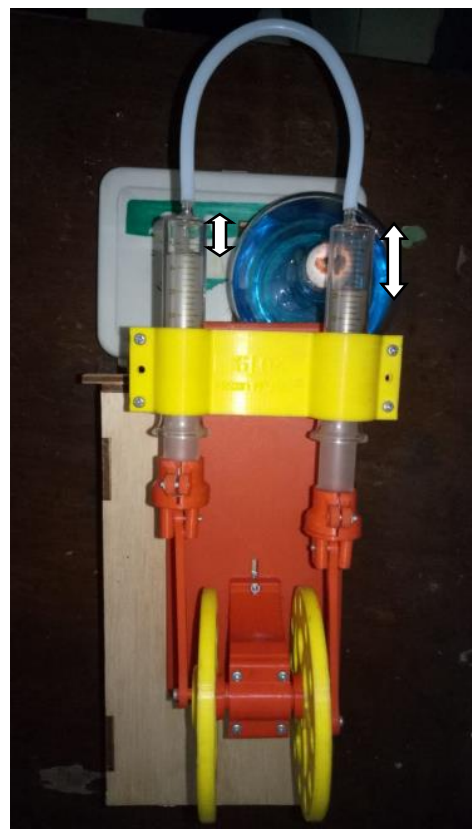

Gambar 4. Mesin Stirling tampak atas.

Anak panah pada Gambar 4 menunjukkan perbedaan volume pada silinder, di mana silinder suhu tinggi volumenya lebih besar dibandingkan dengan silinder suhu rendah. Mesin Stirling dijalankan dengan memposisikan silinder suhu tinggi pada ruang udara maksimum dan silinder suhu rendah pada ruang udara minimum. Kemudian menyalakan spiritus dan meletakkan di bawah silinder suhu tinggi. Tunggu selama beberapa menit sampai tekanan udara pada silinder naik, ditunjukkan dengan pergerakan piston mendorong ke belakang kemudian membantu roda untuk berputar sampai terjadi pergerakan piston yang konstan. 
Hasil uji coba mesin Stirling dilakukan selama beberapa kali, di mana diperoleh hasil sebagai berikut:

1. Waktu yang diperlukan selama proses pemanasan awal sampai piston bergerak adalah 2 menit. Waktu ini digunakan untuk menaikkan tekanan pada silinder suhu tinggi.

2. Durasi dari mesin Stirling bergerak sampai berhenti adalah 4 menit. Setelah mendekati waktu 4 menit mesin Stirling mengalami penurunan kecepatan putaran dan berhenti. Hal ini disebabkan oleh suhu pada silinder dingin naik mendekati suhu pada silinder panas, menyebabkan perbedaan suhu pada silinder tidak cukup untuk mempertahankan gerak.

Berdasarkan percobaan yang dilakukan ketika posisi normal, sejumlah gas ditahan oleh piston dan beranggapan tekanan gas pada kedua sisi piston sama dengan 1 atmosfer. Pada Gambar $\mathbf{5}$ anak panah menunjukkan bahwa saat panas disuplai ke silinder maka tekanan gas dalam silinder akan naik. Kenaikan tekanan gas ini sebanding dengan gaya yang bekerja pada piston.

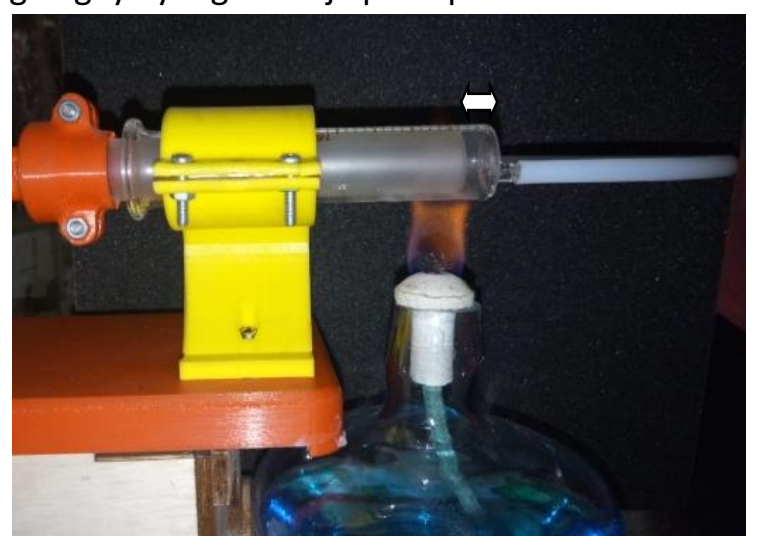

Gambar 5. Piston yang dipanaskan tekanan akan naik.

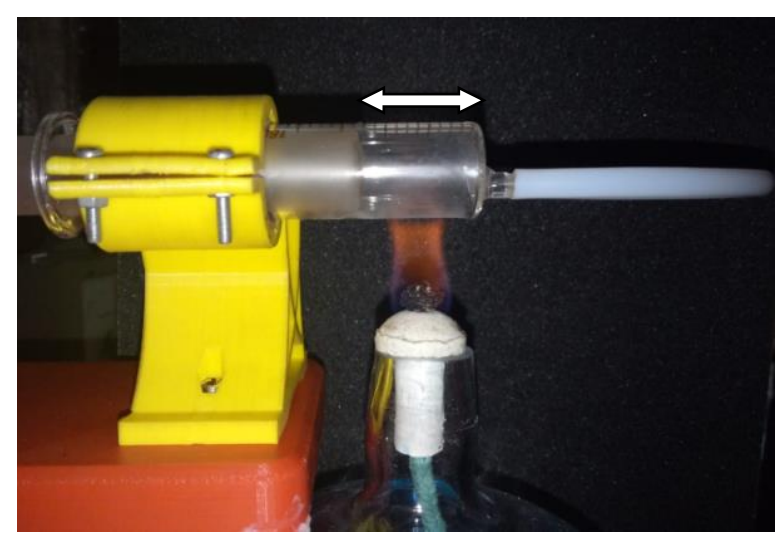

Gambar 6. Volume bertambah lalu tekanan turun.

Pada Gambar 6, anak panah menunjukkan volume pada silinder bertambah, maka tekanan akan turun menjadi 1 atmosfer. Anak panah pada Gambar $\mathbf{7}$ menunjukkan volume maksimum pada silinder yang dingin. Selama mengalami proses pendinginan, tekanan gas pada silinder menjadi lebih rendah dari 1 atmosfer.

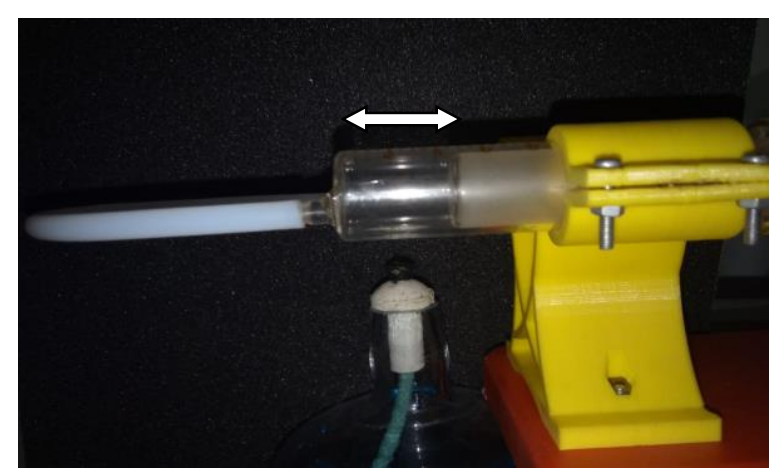

Gambar 7. Piston pada silinder dingin. 


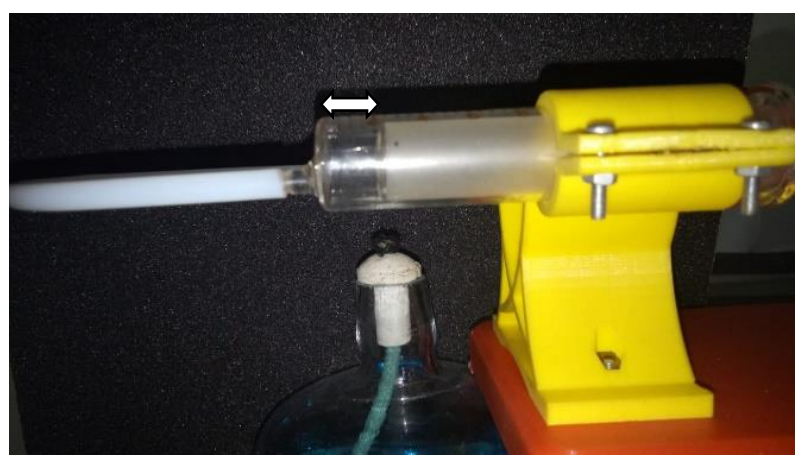

Gambar 8. Piston pada silinder dingin.

Anak panah pada Gambar 8 menunjukkan volume minimum pada silinder yang dingin, kemudian gaya yang diberikan pada piston akan mendorong piston kembali ke posisi semula. Analisa dari hasil penelitian ini dapat dibuatkan tabel dan digambarkan grafiknya berdasarkan hasil pada Gambar 5-8.

Tabel 1. Data kualitatif nilai volume (V) dan tekanan (P) dari pengujian prototype mesin Stirling 3D

\begin{tabular}{cccc}
\hline Gambar & Suhu (T) & Volume (V) & Tekanan (P) \\
\hline 5 & besar & kecil & besar \\
6 & besar & besar & kecil \\
7 & kecil & besar & kecil \\
8 & kecil & kecil & besar \\
\hline
\end{tabular}

Tabel 1 menunjukkan bahwa data foto pada Gambar 5 - 8 telah memberikan data kulitatif untuk suhu (T), volume (V), dan tekanan (P). Data pada Tabel 1 dapat dibuatkan sketsa grafik seperti pada

\section{Gambar 9.}

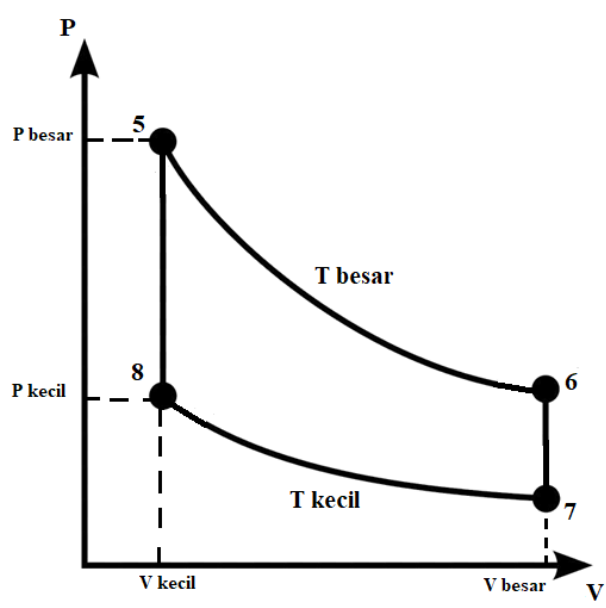

Gambar 9. Sketsa grafik P-V-T pengujian prototype mesin Striling 3D.

Gambar 9 menunjukkan sketsa grafik P-V-T dari pengujian prototype mesin Stirling 3D. Keempat proses pada sketsa grafik Gambar 9 tersebut dapat memprediksi grafik siklus Stirling, di mana satu siklus pergerakan dapat digambarkan grafik dengan area tertutup oleh kurva, siklus inilah yang mengubah panas menjadi energi mekanik. Sketsa grafik pada Gambar 9 sangat mirip dengan grafik siklus Stirling ideal terdiri dari empat proses termodinamika yang bekerja pada fluida kerja yang ditunjukkan oleh Asnaghi maupun Bacheller pada Gambar 10 (Asnaghi et al, 2012; Bachelier, 2009). 


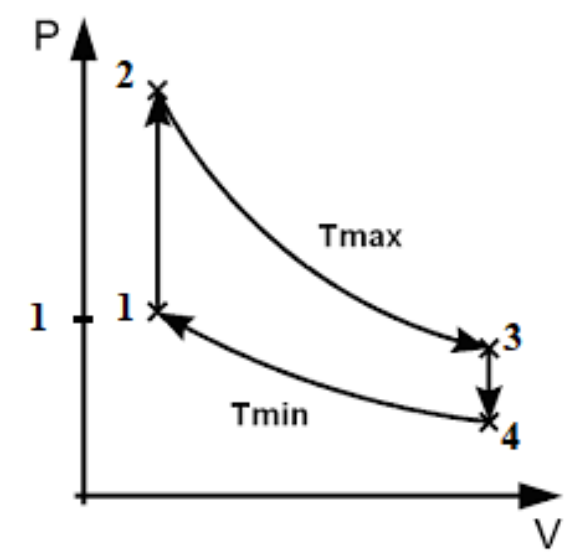

Gambar 10. Grafik tekanan terhadap volume dari siklus Stirling ideal.

Siklus termodinamika yang ideal terdiri dari dua proses regenerative isothermal (suhu konstan) dan dua isometric (volume konstan) (Ahmadi et al, 2017), yang berhubungan dengan gerakan piston dan proses siklus Stirling secara umum yaitu penyerapan panas pada suhu tinggi, penolakan panas pada suhu rendah dan pengiriman pekerjaan ke lingkungan (Kongtragool \& Wongwises, 2006). Hasil penelitian pada pengujian model mesin Stirling 3D ini telah sesuai dan memiliki pola mendekati siklus Stirling ideal ini. Hal ini menunjukkan bahwa prototype model mesin Striling 3D ini sudah dapat digunakan sebagai media pembelajaran fisika materi Termodinamika.

Berdasarkan evaluasi dari tahap perancangan hingga uji coba, didapatkan bahwa masih perlunya memperhatikan beberapa hal ketika menggunakan mesin Stirling ini, yaitu:

1. Selang penghubung antara silinder suhu panas dan suhu dingin dipastikan tidak terjadi kebocoran dan udara benar-benar terisolasi, karena kebocoran yang terjadi membuat mesin tidak bisa berjalan dengan baik.

2. Saat pemanasan awal menempatkan ruang udara maksimum untuk silinder yang dipanaskan dan ruang udara minimum untuk silinder yang bersuhu dingin, agar volume udara yang dipanaskan lebih besar.

3. Memperhatikan penguncian pada tempat silinder agar tidak terlalu kencang supaya saat dipanaskan tidak mengalami keretakan.

4. Bahan 3D printing yang terbuat dari filamen PLA memiliki resistansi suhu yang terbatas sehingga mulai mudah berubah bentuk pada suhu di atas $80^{\circ} \mathrm{C}$. Karena itu keterbatasan ini perlu diperhatikan dalam rancangan terutama ketika komponen-komponen mesin bersentuhan langsung dengan komponen yang secara sengaja dipanaskan.

\section{KESIMPULAN}

Model mesin Stirling dapat dibuat menggunakan teknologi 3D printing. Mesin Stirling ini mampu beroperasi dengan baik selama kurang lebih 6 menit. Prinsip kerja mesin yang memanfaatkan perbedaan suhu ini dapat divisualisasikan dengan baik. Konsep-konsep pendukung mencakup mekanika dapat didemonstrasikan. Melalui model ini eksplorasi lanjut secara kritis dapat dilakukan oleh siswa untuk memperpanjang waktu operasi, penggunaan bahan isolator yang bervariasi, penggunaan pendingin, mengubah inersia roda. Model mesin Stirling 3D printing dapat dipakai sebagai media belajar fisika khususnya untuk membantu memahami materi Termodinamika misalnya materi hubungan P-V-T untuk gas serta konsep-konsep mekanika misalnya hubungan tekanan dan gaya serta torka pada mekanik roda mesin.

\section{UCAPAN TERIMA KASIH}

Penelitian ini ditopang oleh Pusat Studi Pendidikan Sains, Teknologi, dan Matematika (e-SisTeM) Universitas Kristen Satya Wacana melalui program pengembangan media untuk inovatif bekerjasama dan sebagian ditopang oleh Belmawa Kemenristek Dikti melalui Program Pembelajaran Inovatif 2018 dan Yayasan Pendidikan Astra Michale D. Ruslim, PT Astra International, Tbk. 


\section{DAFTAR PUSTAKA}

Ahmadi, M. H., Ahmadi, M. A., \& Pourfayaz, F. (2017). Thermal models for analysis of performance of Stirling engine: A review. Renewable and Sustainable Energy Reviews, Vol. 68, pp. 168-184. https://doi.org/10.1016/j.rser.2016.09.033

Asnaghi, A., Ladjevardi, S. M., Saleh Izadkhast, P., \& Kashani, A. H. (2012). Thermodynamics Performance Analysis of Solar Stirling Engines. ISRN Renewable Energy, 2012, 1-14. https://doi.org/10.5402/2012/321923

Bachelier, C. (2009). Stirling engines A technology overview. Royal Institute of Technology Stockholm, Sweden. Retrieved from http://smarthome.duke.edu/sites/smarthome.duke.edu/files/KTH_Stirling_Engine.pdf

Bataineh, K. M. (2018). Numerical thermodynamic model of alpha-type Stirling engine. Case Studies in Thermal Engineering, 12(December 2017), 104-116. https://doi.org/10.1016/j.csite.2018.03.010

Halliday, D., Resnick, R., Walker, J. (2010). Fisika Dasar Jilid 1 (7th ed.). Jakarta: Erlangga.

Helinda, Y. (2016). Pengembangan alat peraga mesin stirling sederhana pada pokok bahasan termodinamika kelas xi sma. Institut Agama Islam Negeri Raden Intan. Retrieved from http://repository.radenintan.ac.id/2827/1/SKRIPSI_FIX_YEYEN.pdf

Kongtragool, B., \& Wongwises, S. (2006). Thermodynamic analysis of a Stirling engine including dead volumes of hot space, cold space and regenerator. Renewable Energy, 31(3), 345-359. https://doi.org/10.1016/j.renene.2005.03.012

Nicr-ni, T. (1816). Stirling engine Stirling engine. Connect, 1-9.

Putrawangsa, S., \& Hasanah, U. (2018). Integrasi Teknologi Digital Dalam Pembelajaran Di Era Industri 4.0Kajian dari Perspektif Pembelajaran Matematika. Jurnal Tatsqif, 16(1), 42-54. https://doi.org/https://doi.org/10.20414/jtq.v16i1.203

Religia, R. (2017). Pengembangan KIT Sederhana Stirling Engine pada Materi Termodinamika sebagai Media Pembelajaran Fisika SMA. Inovasi Pendidikan Fisika, 6(3), 113-119.

Romanelli, A. (2017). Alternative thermodynamic cycle for the Stirling machine. American Journal of Physics, 85(12), 926-931. https://doi.org/10.1119/1.5007063

Saputro, V. C. E., Prabowo, \& Admoko, S. (2019). Pengembangan Alat Peraga Mesin Carnot Sebagai Media Pembelajaran dengan Model Pembelajaran Inkuiri Terbimbing. Inovasi Pendidikan Fisika, 08(02), 521-524.

Setyo, N., \& Financia, M. (2018). Pelatihan Desain dan Pembuatan Objek 3 Dimensi Menggunakan Printer 3D Sebagai Pendukung Program Keterampilan di MAN 1 Jember. Seminar Nasional Hasil Penelitian Dan Pengabdian Masyarakat, 44-46.

Singh, U. R., \& Kumar, A. (2018). Review on solar Stirling engine: Development and performance. Thermal Science and Engineering Progress, Vol. 8. https://doi.org/10.1016/j.tsep.2018.08.016

Walker, G. (1985). Chapter 1 Introduction. Developments in Soil Science, 14(C), 1-5. https://doi.org/10.1016/S0166-2481(08)70131-4

Yuliyani, I., \& Irwan, M. (2013). Pembuatan dan Pengujian Prototipe Mesin Stirling Tipe Gamma. Prosiding Industrial Research Workshop and National Seminar, 4(08), 286-289. https://doi.org/http://dx.doi.org/10.35313/irwns.v4i0.322 